ORIGINAL ARTICLE

\title{
Off seasonal and pre-seasonal assessment of circulating energy sources during prolonged running at the anaerobic threshold in competitive triathletes
}

\author{
B Knoepfli, M C Riddell, E Ganzoni, A Burki, B Villiger, S P von Duvillard
}

Br J Sports Med 2004;38:402-407. doi: 10.1136/bjsm.2002.003442

See end of article for authors' affiliations

Correspondence to Professor von Duvillard, Human Performance Laboratory, Department of Health, Kinesiology \& Sports Studies, Texas A\&M University-

Commerce, PO Box 3011 , Commerce, TX 75429, USA; serge_vonduvillard@ tamu-commerce.edu

Accepted 20 May 2003

\begin{abstract}
Objectives: To compare changes in circulating energy sources during prolonged exercise in off season (OS) and pre-season (PS) training of triathletes.

Methods: Nine athletes of the Swiss national triathlon team (three female, mean (SD) age 28.7 (4.9) years, height $169.8(6.0) \mathrm{cm}$, weight $57.0(6.2) \mathrm{kg}, \dot{V O}_{2} \mathrm{MAX} 66.5$ (5.3) $\mathrm{ml} / \mathrm{min} / \mathrm{kg}$; six male, mean (SD) age 24.0 (4.1) years, height $181.4(6.9) \mathrm{cm}$, weight $73.5(6.0) \mathrm{kg}, \dot{V} \mathrm{O}_{2} \operatorname{MAX} 75.9(4.9) \mathrm{ml} / \mathrm{min} / \mathrm{kg}$ ) were tested twice (2.5 months apart) during a $25 \mathrm{~km}$ aerobic capacity test run at the end of the OS and just before the season. The average training load during the OS was $9.9 \mathrm{~h} /$ week, and this increased to $14.4 \mathrm{~h} /$ week in the PS. With heart rates as reference, exercise intensity during the aerobic capacity test was $97.0(4.9) \%$ of the anaerobic threshold and $91.2(4.5) \%$ of $\dot{V}_{2} \mathrm{MAX}$. Blood samples were collected before, during, and after the aerobic capacity test. Samples were collected every $5 \mathrm{~km}$ during three minute rest intervals.

Results: Blood was analysed for triglyceride (TG), free fatty acids, cholesterol, high density lipoprotein cholesterol, glucose, insulin, lactate, and changes in plasma volume. A two factor (season by distance) repeated measures analysis of variance revealed an increase in capacity for prolonged exercise in the PS by a decrease in running intensity during the aerobic capacity test $(\%$ of speed at $2.0 \mathrm{mmol} / \mathrm{l}$ lactate threshold, $p=0.008)$, an increase in running speed at the anaerobic threshold $(p=0.003)$ and at 4.0 and $2.0 \mathrm{mmol} / \mathrm{l}(\mathrm{p}<0.001)$ of the lactate threshold. A significant season by distance interaction was found for TG $(p<0.001)$. TG concentrations peaked at $5 \mathrm{~km}$ and decreased logarithmically throughout the OS $(1.48(0.34)$ to $0.86(0.20) \mathrm{mmol} / \mathrm{l})$ and PS $(1.90(0.31)$ to $0.73(0.18) \mathrm{mmol} / \mathrm{l})$ tests. From the OS to the $\mathrm{PS}$, there was an increase in the difference in TG at 5-15 km with a concomitant increase at $2.0 \mathrm{mmol} / \mathrm{l}$ of the lactate threshold. The peak TG concentrations at $5 \mathrm{~km}$ followed by a logarithmic decrease suggest that TG may also provide circulating energy. A greater logarithmic decrease in TG occurred in the PS than in the OS, indicating a higher rate of use. There was an increase in the difference in TG at 5-15 km similar to the increase in the speed at $2.0 \mathrm{mmol} / \mathrm{l}$ of the lactate threshold between the two seasons. Glucose, insulin, lactate, and free fatty acids were similar in the two seasons.

Conclusion: Free fatty acid and TG concentrations were much higher than expected, and the two training seasons showed significantly different patterns of TG concentration during prolonged running. These responses may be related to aerobic capacity of prolonged exercise.
\end{abstract}

$M$ easurements of oxygen consumption $\left(\dot{\mathrm{V}}_{2}\right)$ and lactate concentrations are commonly used to assess aerobic performance. They are regarded as measures of cardiopulmonary and muscle performance. Numerous reference values of maximal oxygen consumption ( $\left.\dot{\mathrm{V}}_{2} \mathrm{MAX}\right)$ are available for the general population, as well as for various sports. It is generally accepted that a $\dot{\mathrm{V}}_{2} \mathrm{MAX}$ value exceeding $70.0 \mathrm{ml} / \mathrm{kg} / \mathrm{min}$ is a favourable precondition for international competition. Athletes with $\dot{\mathrm{V}}_{2} \mathrm{MAX}$ below $60.0 \mathrm{ml} / \mathrm{kg} / \mathrm{min}$ may be unable to succeed at this level. Previous studies indicate a poor relation between $\dot{\mathrm{V}}_{2} \mathrm{MAX}$ and competitive performance in triathletes ${ }^{2}$ and long distance runners. ${ }^{3}$ Performance variables measured at a submaximal intensity - that is, anaerobic or lactate thresholdmay provide an indication of competition performance in well trained, long distance athletes. ${ }^{2}{ }^{4}$ Other factors such as anaerobic threshold (AT), intracellular substrate availability, circulating energy sources, and economy of motion may be more important in prolonged endurance competitions.

The two primary substrates used by working skeletal muscle are carbohydrates and fats..$^{5-8}$ It has been suggested that endurance training leads to metabolic and cellular adaptations that allow trained muscle to rely more on fat for oxidation and thus spare carbohydrates. ${ }^{9-13}$ Some investigators have suggested that this is of major importance in delaying muscle fatigue, as muscle glycogen and blood glucose can be spared. Oberholzer et al $^{14}$ have calculated that intracellular substrate stores could account for about $50 \%$ of the substrate needed in an ultra-long distance event $(25 \%$ lipids, $22 \%$ glycogen). The remaining energy should be provided by the blood and may depend on blood glucose and fat concentrations. Felig et $a l^{15}$ reported depletion of circulating glucose in healthy men engaged in running. Declining glucose concentrations without carbohydrate supplementation have been reported. ${ }^{57}$ It has been shown that blood glucose concentrations are increased during exercise with carbohydrate supplementation. ${ }^{16}{ }^{17}$ Long term training induces a reduction in glucose turnover at moderate exercise intensity ${ }^{68}$ probably due to an increase in fat

Abbreviations: $A C T$, aerobic capacity test; $A P T$, aerobic power test; $A T$, anaerobic threshold; FFA, free fatty acid; LT, lactate threshold; TG, triglyceride; $\dot{\mathrm{V}}_{2} \mathrm{MAX}$, maximal oxygen consumption 
utilisation. It is generally accepted that maintenance of carbohydrate availability and oxidation will lead to enhanced endurance exercise performance. ${ }^{18}$ Therefore, we expected that, during prolonged exercise without carbohydrate supplementation, glucose delivery to contracting muscle would become a limiting factor, ${ }^{5}$ and changes in carbohydrate metabolism would reflect glucose, lactate, and insulin concentration in the serum. These hypotheses may be contrary, as Ahlborg et al ${ }^{19}$ found only small modifications in circulatory variables. They measured highly significant changes in glycogen stores in the working muscle. Others reported that, during high intensity exercise, the blood glucose concentration does not have any effect on skeletal muscle glycogen metabolism. ${ }^{20}{ }^{21}$ Furthermore, without glucose supplementation in most running performance studies, blood glucose concentrations do not decline, ${ }^{17} 2223$ although Knapik et $a l^{24}$ found an increase in blood glucose concentration at $85 \%$ of $\dot{\mathrm{V}}_{2} \mathrm{MAX}$. Therefore, the intensity of the exercise and the training state seem to be key factors in this issue.

Prolonged exercise of moderate intensity has been shown to result in a time dependent increase in fat oxidation. ${ }^{6} 825$ After endurance training, the dependence on fat oxidation becomes more pronounced..$^{5813}$ The increased reliance on fat oxidation appears to depend on an increase in intramuscular triglyceride (TG) concentration and the availability of plasma free (non-esterified) fatty acids (FFAs). ${ }^{525} \mathrm{In}$ an extreme endurance race, it was shown that the volume of intracellular lipid deposits was reduced from $1.3 \%$ to $0.3 \%$ of the muscle cell's volume. ${ }^{14}$ About $50 \%$ of the substrate needed could be obtained from the intracellular substrate stores in that particular ultra-long distance event. Therefore the availability of circulating fat sources appears to be important. Oberholzer et $a l^{14}$ support the hypothesis that increasing fat availability immediately before exercise enhances the capacity of trained subjects to perform prolonged exercise. ${ }^{26}$ It has been suggested that medium chain TG and FFAs may be a readily available energy source for the working muscle. ${ }^{27-29}$ The pattern of substrate use depends on the interaction between exercise intensity induced response and endurance volume induced response. ${ }^{6}$ Carbohydrate availability is regulated by exercise intensity; however, the regulation of lipid metabolism seems to be more complex. ${ }^{8}$ Circulating energy sources in well trained athletes at exercise intensities comparable to competition have been studied. Despite the well known presence of TG in skeletal muscles, regulation of this substrate is not well defined.

Therefore the purpose of this study was to examine changes in circulating energy sources, specifically TG and FFAs, that occur during prolonged exercise at the AT in elite athletes before preparation for the season (off season (OS)) and before the season (pre-season (PS)). From experience, these athletes tend to show better performances in prolonged exercise during their PS than their OS schedule. To assess these performances, specific tests of aerobic capacity were carried out before the trials.

\section{METHODS \\ Design}

Triathletes were tested twice (2.5 months apart; in an "untrained" state at the end of the OS and in a "trained" state just before the season (PS)) using a maximal aerobic power test (APT) and an aerobic capacity test (ACT, $25 \mathrm{~km}$ run). They were invited to participate in identically structured days for both seasons. APT was performed on the first day, and ACT was performed 48 hours later. On test days, training sessions were reduced and food intake was the same. Athletes served as their own controls.
Table 1 Anthropometric characteristics of the athletes

\begin{tabular}{|c|c|c|c|c|c|}
\hline & No & Age (years) & Height $(\mathrm{cm})$ & Weight (kg) & Body fat (\%) \\
\hline Women & 3 & 28.7 (4.9) & $169.8(6.0)$ & $57.0(6.2)$ & $10.9(4.4)$ \\
\hline Men & 6 & $24.0(4.1)$ & $181.4(6.9)$ & $73.5(6.0)$ & $8.3(3.1)$ \\
\hline
\end{tabular}

\section{Subjects}

Data are presented for nine triathletes of the Swiss national team who completed both tests. Table 1 summarises their phỵsical characteristics.

$\dot{\mathrm{VO}}_{2} \mathrm{MAX}$ measured on the treadmill was 69.0 (6.2) ml $/ \mathrm{kg} /$ min and $79.1(4.8) \mathrm{ml} / \mathrm{kg} / \mathrm{min}$ in the female and male athletes respectively (mean of the two seasons). Running speed at AT was $16.5(0.8) \mathrm{km} / \mathrm{h}$ and $18.4(0.9) \mathrm{km} / \mathrm{h}$ and represented $84.2(2.8) \%$ of their maximum speed (mean of the two seasons). During the OS, the average training load was 9.9 (4.9) h/week. During the PS, it increased significantly to $14.4(4.6) \mathrm{h} /$ week $(\mathrm{p}=0.03)$. The training sessions consisted of 27.6 (19.8)\% jogging, 31.4 (15.9)\% cycling, 27.2 (16.2)\% swimming, and $13.3(8.0) \%$ other sports. None of the subjects were smokers at the time of the study; however, one had a history of short term smoking. The ethics committee of Davos approved the study protocol. Before participation, all subjects gave written informed consent.

Nutritional intake and physical activity before testing Nutritional intake was quantitatively measured for one week before each ACT using a questionnaire (Nutricare, Basel, Switzerland). Responses were confirmed by personal interviews. An identical breakfast was consumed in the morning of each ACT. Three days before the ACT, all athletes trained below $90 \%$ of their AT and exercised no more than $30 \mathrm{~min} /$ day except for the APT.

\section{Aerobic power test (APT)}

Subjects performed a progressive $\dot{\mathrm{V}}_{2} \mathrm{MAX}$ treadmill test protocol with 2.5 minute stages separated by 30 second rest periods. Testing began at $9 \mathrm{~km} / \mathrm{h}$ at $1.5 \%$ grade. Intensity was increased at each stage by $1.8 \mathrm{~km} / \mathrm{h}$. Blood samples were taken from the earlobe during each rest period. Blood lactate concentration was determined with a YSI model 23L analyser (Yellow Springs Instrument Co, Yellow Springs, Ohio, USA). $\dot{\mathrm{V}}_{2}$ and carbon dioxide production $\left(\dot{\mathrm{V}}_{\mathrm{CO}_{2}}\right)$ were determined (30 second averages) with an open air spirometry system (EOS/Sprint, Jäger, Würzburg, Germany). The test was terminated when the subject could no longer maintain the exercise intensity. At exhaustion, all subjects attained a respiratory exchange ratio of $\geqslant 1.1$ and a plateau in $\dot{\mathrm{V}}_{2}$. The AT was determined using the protocol of Lehmann et al, , $^{30}$ which uses the ratio of lactate $/ \dot{\mathrm{V}}_{2}$ for each stage of the test. By this method, the minimal workload dependent ratio of lactate $/ \dot{\mathrm{V}}_{2}$ (minimum lactate equivalent) determines the optimal working economy. Based on this minimal lactate equivalent, AT was estimated by adding $1.5 \mathrm{mmol} / \mathrm{l}$ lactate. Heart rate was determined with an electrocardiograph.

\section{Aerobic capacity test (ACT)}

The ACT was conducted in the field between 0900 and 1100. The meteorological data during the capacity tests were provided from a measuring station of the Swiss Meteorological Institution stationed in the running field. Air temperature increased during the PS from $-5.7^{\circ} \mathrm{C}$ to $1.0^{\circ} \mathrm{C}$ and during the OS from $5.9^{\circ} \mathrm{C}$ to $9.1^{\circ} \mathrm{C}$. The relative humidity was $96 \%$ during the first investigation and $95 \%$ during the second. The respective barometric pressures were 722 and 
$721 \mathrm{~mm} \mathrm{Hg}$. On both days, there was no precipitation and the ground was not covered with snow.

The ACT was carried out on flat terrain in a $2.5 \mathrm{~km}$ loop. All subjects completed a total distance of $25 \mathrm{~km}$. Athletes were asked to perform at a very high and constant aerobic exercise intensity (97\% of their individual AT). The reference intensity was determined by the APT, and the exercise intensity was constantly monitored and controlled by the athletes and the investigators using heart rate (Sport Tester; Polar, Oy, Finland). The ACT was interrupted every $5 \mathrm{~km}$ for three minute rest periods. During rest periods, all subjects drank $200 \mathrm{ml}$ water, and blood samples were taken from an indwelling catheter in an antecubital vein.

\section{Laboratory tests}

Blood samples were collected nine times: 24 hours before, 30 minutes before, at $5 \mathrm{~km}, 10 \mathrm{~km}, 15 \mathrm{~km}, 20 \mathrm{~km}, 25 \mathrm{~km}$, and six hours, and 24 hours after the ACT. They were analysed for the variables listed in table 2. Changes in plasma volume were determined from haemoglobin and packed cell volume measurements by the method of Wright et al. ${ }^{31}$ The laboratory methods used for each of the above analyses are given in table 2 .

\section{Statistical analysis}

Results were analysed as a comparison of OS $v$ PS using a two factor (season by distance) repeated measures analysis of variance. A Tukey post hoc test was used when indicated. $\mathrm{p}<0.05$ was considered significant. For comparison, the distance factor included measurements before and after the ACT, unless depicted otherwise.

\section{RESULTS}

Table 3 lists energy intake and percentage energy supply from carbohydrates, fats, and proteins before the trial.

ACT was conducted at an almost uniform running intensity averaging 97.0 (4.9)\% (OS = 94.6 (5.1)\%; PS = $99.7(4.1) \%)$ of the individual AT as assessed from the heart rate. Therefore the group fulfilled the predetermined criteria for running intensity. This corresponded to an average of 91.2 (4.5)\% $(\mathrm{OS}=92.3(5.9) \%$; PS $=90.1(2.6) \%)$ of the $\dot{\mathrm{V}}_{2} \mathrm{MAX}$. Mean lactate concentration was 3.0 (1.9) mmol/l $(\mathrm{OS}=2.6$ (2.2) $\mathrm{mmol} / \mathrm{l} ;$ PS $=3.4$ (1.4) $\mathrm{mmol} / \mathrm{l})$. Plasma volumes, determined using haemoglobin concentration and packed cell volume, were similar for the two seasons and did not change significantly during the ACT.

Table 4 shows the aerobic power variables measured in the APT and aerobic capacity variables measured in the ACT in the OS and PS. $\dot{\mathrm{VO}}_{2} \mathrm{MAX}$ was significantly lower in the PS than in the OS $(\mathrm{p}<0.05)$. Speeds at AT, $4.0 \mathrm{mmol} / \mathrm{l}$ lactate threshold (LT), and $2.0 \mathrm{mmol} / \mathrm{l}$ LT were all significantly greater in the PS than in the OS $(p<0.005)$. Running intensity in the ACT expressed as a percentage of the speed
Table 3 Energy intake in the off season and pre-season before the trial

\begin{tabular}{lllll}
\hline & $\begin{array}{l}\text { Energy } \\
\text { (kcal/day) }\end{array}$ & $\begin{array}{l}\text { Carbohydrate } \\
(\%)\end{array}$ & Fat (\%) & Protein (\%) \\
\hline Off season & $2956(750)$ & $66.1(6.9)$ & $15.4(4.2)$ & $18.4(4.8)$ \\
Pre-season & $3270(856)$ & $68.2(5.1)$ & $15.2(3.3)$ & $16.7(3.3)$ \\
\hline
\end{tabular}

Data are mean (SD) $(n=9)$. There were no significant differences

between the seasons.

at $2.0 \mathrm{mmol} / \mathrm{l}$ LT was significantly lower in the PS than in the OS $(p=0.008)$. Running speed was not significantly different between the seasons $(p>0.05)$. However, there was a tendency for an increase in running speed in the PS compared with the OS $(\mathrm{p}=0.096)$, although running intensity (expressed as a percentage of the speed at $2 \mathrm{mmol} / \mathrm{l}$ LT) was lower. In the ACT, the speed/intensity ratio was significantly $(\mathrm{p}<0.001)$ higher during the PS than the OS, indicating increased speed in relation to intensity.

Figure 1 shows serum TG concentrations. TG peaked at $5 \mathrm{~km}$ and then decreased logarithmically during the ACT in both trials $(\mathrm{p}<0.001$, for data collapsed across season). A significant season by distance interaction for TG concentrations was found $(\mathrm{p}<0.001)$. At $5 \mathrm{~km}$, it was 1.48 (0.34) $\mathrm{mmol} / \mathrm{l}$ in the OS compared with 1.90 (0.31) $\mathrm{mmol} / \mathrm{l}$ in the PS $(\mathrm{p}<0.001)$. The two curves crossed at $10 \mathrm{~km}$ and were $0.98(0.22)$ and $0.73(0.18) \mathrm{mmol} / \mathrm{l}$ at $25 \mathrm{~km}$ in the OS and PS respectively $(\mathrm{p}=0.016)$. In all athletes, the decrease in TG concentrations between 5 and $15 \mathrm{~km}$ was more pronounced in the PS than the OS. The difference in TG concentrations between 5 and $15 \mathrm{~km}$ increased from the OS to the PS similarly to the increase in speed at $2.0 \mathrm{mmol} / \mathrm{l} \mathrm{LT}$ (fig 2). Plasma FFA concentrations were similar in the two seasons before, during, and after the ACT (fig 3). FFA concentrations averaged $0.56(0.52) \mathrm{mmol} / \mathrm{l}$ before the ACT (data collapsed across season and the time before the ACT). At $5 \mathrm{~km}$, values were $0.91(0.27) \mathrm{mmol} / \mathrm{l}$ and increased to $2.66(0.74) \mathrm{mmol} / \mathrm{l}$ by $10 \mathrm{~km}(\mathrm{p}<0.001)$. At $15 \mathrm{~km}$, they decreased to $1.89(0.60) \mathrm{mmol} / \mathrm{l}(\mathrm{p}<0.001)$ and remained unchanged at 20 and $25 \mathrm{~km}$.

Figure 4 shows serum glucose concentrations. They were similar between seasons and increased from $4.5(0.9) \mathrm{mmol} / \mathrm{l}$ $(810$ (152) $\mathrm{mg} / \mathrm{l}) 30 \mathrm{~min}$ before the start to 7.7 (1.4) $\mathrm{mmol} / \mathrm{l}$ (1386 (233) mg/l) at $5 \mathrm{~km}(\mathrm{p}<0.001)$. Glucose decreased throughout the ACT to 5.2 (1.2) mmol/l (936 (226) mg/l) by $25 \mathrm{~km}(\mathrm{p}<0.001)$. One athlete reached hypoglycaemia (glucose concentration below $2.8 \mathrm{mmol} / \mathrm{l}$ or $500 \mathrm{mg} / \mathrm{l}$ ) during the ACT in the PS. Serum insulin concentrations were also similar between seasons and decreased from 13.1 (7.2) $\mu \mathrm{U} /$ $\mathrm{ml}$ at $5 \mathrm{~km}$ to $7.6(4.3) \mu \mathrm{U} / \mathrm{ml}$ by $25 \mathrm{~km}(\mathrm{p}<0.001)$. Blood lactate did not differ between the seasons and decreased from

Table 2 Laboratory variables and methods

\begin{tabular}{|c|c|c|c|}
\hline Substance & Medium & Method & Instrument \\
\hline \multicolumn{4}{|c|}{ Primary outcome variables } \\
\hline Triglyceride & Serum & Enzymatic (PAP) & Cobas Mira, Roche \\
\hline Free fatty acids & Serum & Enzymatic & Cobas Mira, Roche \\
\hline \multicolumn{4}{|c|}{ Secondary outcome variables } \\
\hline Glucose & Serum & Glucose dehydrogenase & Cobas Mira, Roche \\
\hline Insulin & Serum & ELISA & $\begin{array}{l}\text { ES (Enzym-System) 200, } \\
\text { Boehringer }\end{array}$ \\
\hline Lactate & Blood & Enzymatic & Cobas Mira, Roche \\
\hline Haemoglobin & Blood & Photometric & K 1000, Digitana (Horgen) \\
\hline Erythrocytes & Blood & Capillary count & K 1000, Digitana (Horgen) \\
\hline
\end{tabular}


Table 4 Aerobic power and capacity variables in the off season (OS) and pre-season (PS)

\begin{tabular}{|c|c|c|c|c|c|c|}
\hline & \multicolumn{2}{|c|}{ Women (n = 3) } & \multicolumn{2}{|l|}{ Men $(n=6)$} & \multicolumn{2}{|l|}{ Total $(\mathbf{n}=9)$} \\
\hline & $\overline{\text { OS }}$ & PS & $\overline{\text { OS }}$ & PS & $\overline{\text { OS }}$ & PS \\
\hline \multicolumn{7}{|l|}{ APT } \\
\hline$b_{2} \operatorname{MAX}(\mathrm{ml} / \mathrm{min} / \mathrm{kg})$ & $66.5(5.3)$ & $63.1(6.9)$ & $75.9(4.9)$ & $72.9(3.8)$ & $72.8(6.6)^{*}$ & $69.6(6.7)$ \\
\hline Speed at AT $(\mathrm{km} / \mathrm{h})$ & $16.6(0.6)$ & $16.5(1.0)$ & $17.8(0.6)^{* \star \star \star}$ & $19.1(0.7)$ & $17.4(0.8)^{* \star *}$ & $18.2(1.5)$ \\
\hline Speed at $4 \mathrm{mmol} / \mathrm{l} \mathrm{LT}(\mathrm{km} / \mathrm{h})$ & $17.2(0.3)$ & $17.7(0.2)$ & $19.2(0.5)^{\star \star \star \star *}$ & $20.9(0.5)$ & $18.5(1.1)^{* \star \star *}$ & $19.8(1.6)$ \\
\hline Speed at $2 \mathrm{mmol} / \mathrm{l} \mathrm{LT}(\mathrm{km} / \mathrm{h})$ & $15.1(1.3)^{\star * *}$ & $16.2(0.9)$ & $16.8(0.5)^{\star * \star *}$ & $18.5(0.4)$ & $16.2(1.2)^{\star \star \star \star *}$ & $17.7(1.3)$ \\
\hline \multicolumn{7}{|l|}{ ACT } \\
\hline Speed $(\mathrm{km} / \mathrm{h})$ & $14.3(1.4)$ & $15.0(0.7)$ & $16.9(0.8)$ & $17.1(0.8)$ & $16.1(1.6)$ & $16.4(1.3)$ \\
\hline Intensity (\% of speed at $2 \mathrm{mmol} / \mathrm{I} \mathrm{LT}$ ) & $95.2(5.9)$ & $92.7(3.6)$ & $100.8(3.8)^{* *}$ & $92.6(3.4)$ & $98.9(5.1)^{* *}$ & 92.6 (3.2) \\
\hline
\end{tabular}

3.4 ( 1.0$) \mathrm{mmol} / \mathrm{l}$ at $5 \mathrm{~km}$ to 2.8 (1.9) $\mathrm{mmol} / \mathrm{l}$ by $25 \mathrm{~km}(\mathrm{p}=$ 0.034 ). Plasma volume did not change significantly in the two seasons or during the ACT.

\section{DISCUSSION}

When comparing different training seasons with changes in circulating energy sources that occur during prolonged exercise, our study is in the forefront of assessing elite athletes at the AT (aerobic high intensity performance) during $25 \mathrm{~km}$ running. In this study, FFA and TG concentrations were much higher than expected, yielding interesting results. (a) During prolonged exercise, FFA and TG concentrations peaked at 5 and $10 \mathrm{~km}$ followed by a logarithmic decrease. (b) The two training seasons (OS and PS) had significantly different patterns of TG concentrations during prolonged and high intensity running. (c) In all athletes, the decrease in TG concentration between 5 and $15 \mathrm{~km}$ was more pronounced in the OS than the PS, and the difference increased similarly in the $2.0 \mathrm{mmol} / \mathrm{l}$ LT. (d) During prolonged exercise, the pattern of glucose, insulin, and FFA concentration did not differ between the two seasons.

It is generally accepted that TG is the main intracellular substrate, along with FFAs from adipose tissue. Our findings suggest that circulating TG may have a role in energy provision also. In our athletes, the serum TG concentrations peaked at $5 \mathrm{~km}$ and subsequently decreased logarithmically during the ACT. We observed a high initial peak and a subsequent decrease in circulating TG. This may be due to the

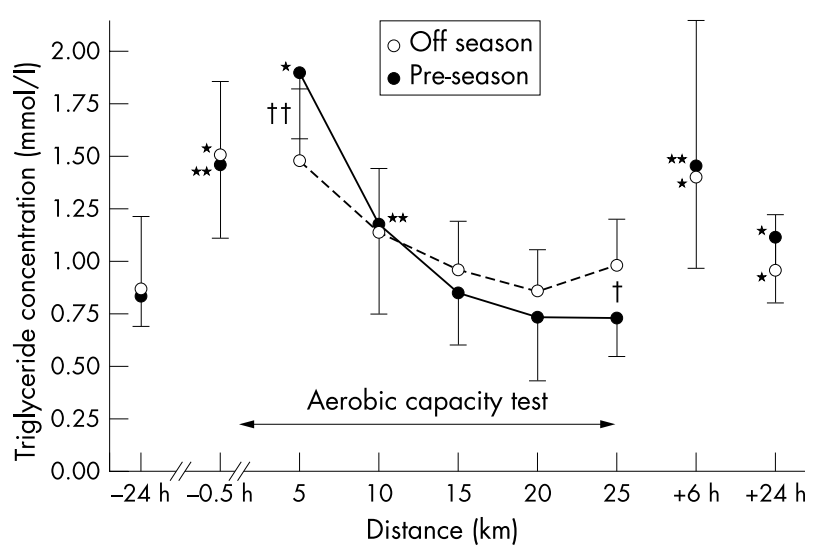

Figure 1 Triglyceride concentration before, during, and after the aerobic capacity test (ACT) in the off season (OS) and pre-season (PS) (n $=9$ ). Values are mean (SD). $-24 \mathrm{~h},-0.5 \mathrm{~h},+6 \mathrm{~h}$, and $+24 \mathrm{~h}$ indicate 24 hours before, 0.5 hours before, 6 hours after, and 24 hours after the start of the ACT. Season by distance interaction $p<0.001$; no season main effect; ${ }^{*},{ }^{* *}$ values different from previous distance $(p<0.05$ and $p<0.001$ respectively); $\dagger, \uparrow+O S$ different from PS $(p<0.05$ and $p<0.001$ respectively). subjects being well trained and the high exercise intensity in this study. When the two training seasons are compared, in the PS the initial TG concentration was significantly higher. The two curves crossed at $10 \mathrm{~km}$, and the TG concentrations were lower in the PS than the OS at 15, 20, and $25 \mathrm{~km}$. The resting concentrations of TG before and after the ACT did not differ between the two training seasons. As our athletes increased their performance concentration for prolonged exercise, a training effect possibly reflects this occurrence. In the PS, the better trained athletes may show increased availability of serum TG at the beginning of the run and improved delivery to the working tissue during the ACT. Moreover, the difference in TG concentration at 5-15 km increased similarly to the speed at $2.0 \mathrm{mmol} / \mathrm{l} \mathrm{LT}$ (fig 2). FFAs showed an initial increase $(2.66 \mathrm{mmol} / \mathrm{l})$ at $10 \mathrm{~km}$ and stabilised at about $2.0 \mathrm{mmol} / \mathrm{l}$. The maximal FFA concentrations observed were twice as high (or more) as the values found in other studies carried out at moderate intensity. ${ }^{5828} 29$ The pattern with an initial increase in FFAs during the first 30 minutes is in line with the findings of Romijn et $a l^{8}$ and depends on the exercise intensity. Furthermore, the studies conducted in untrained subjects showed a continuous increase in plasma FFAs during prolonged exercise. ${ }^{5} 825$ In well trained athletes, however, there is evidence that FFA concentration peaks at the beginning of an intensive workload and decreases after about 30 minutes. ${ }^{827} 28$ Although we did not find significant differences between the different training seasons, we noted a similar or delayed pattern in TG concentration. Other studies ${ }^{5252}$ show diminished circulating plasma FFA concentrations during prolonged exercise as a result of training.

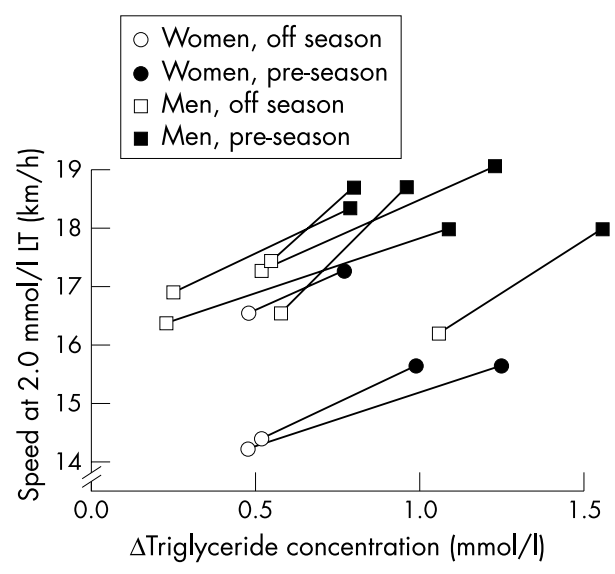

Figure 2 Running speed at the $2.0 \mathrm{mmol} / \mathrm{l}$ lactate threshold (LT) compared with the decrease $(\Delta)$ in serum triglyceride concentration between 5 and $15 \mathrm{~km}$ during the aerobic capacity test $(n=9)$. 


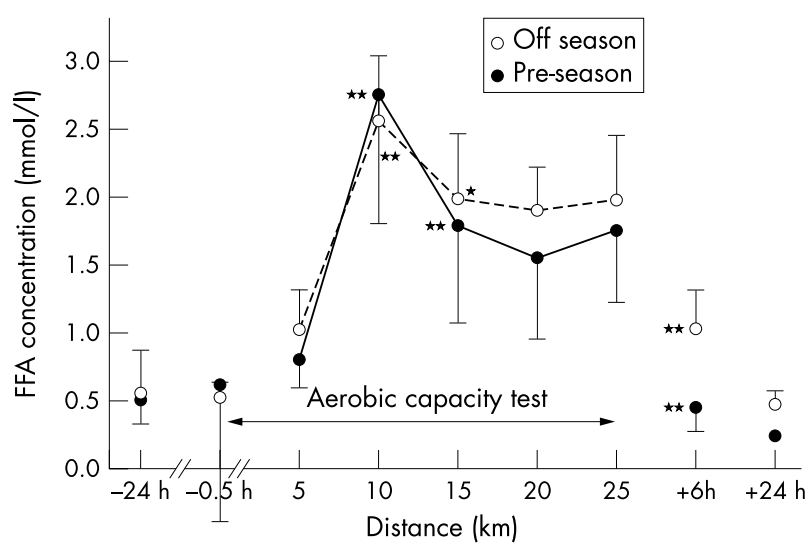

Figure 3 Free fatty acid (FFA) concentration before, during, and after the aerobic capacity test (ACT) in the off season and pre-season $(n=9)$. Values are mean (SD). $-24 h,-0.5 h,+6 h$, and $+24 h$ indicate 24 hours before, 0.5 hours before, 6 hours after, and 24 hours after the start of the ACT. No season main effect; no season by distance interaction; *, ** values different from previous distance $(p<0.05$ and $\mathrm{p}<0.001$ respectively).

Muscle glycogen concentration has been suggested to be the key factor contributing to aerobic capacity in prolonged high intensity exercise. ${ }^{33}$ Performance time during a given workload can be influenced by diet, and there is a strong correlation between initial muscle glycogen concentration and exercise time. ${ }^{34}{ }^{35}$ Although we did not measure glycogen concentrations in the athletes in our study, we attempted to standardise nutritional intake and training before the test to reduce modulation in glycogen concentrations. We found a continuous and significant decrease in serum glucose during exercise. However, the athletes (except one) did not show hypoglycaemic concentrations $(<2.8 \mathrm{mmol} / \mathrm{l})$. In the PS, hypoglycaemia occurred in one athlete at $15 \mathrm{~km}$, but he recovered fully at 20 and $25 \mathrm{~km}$ by adjusting his running speed. As previously discussed, differences in circulating glucose concentrations during prolonged exercise between trained and untrained subjects may depend mainly on exercise intensity and the subject's performance. We did

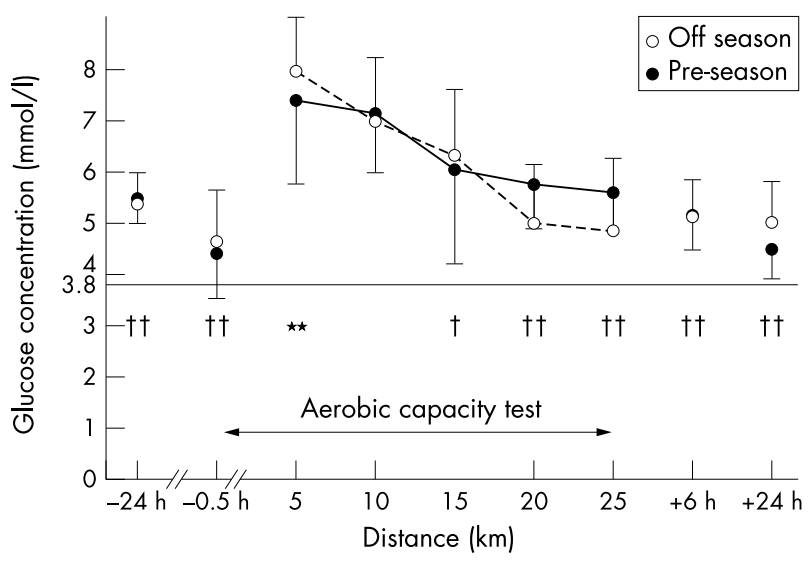

Figure 4 Glucose concentration before, during, and after the aerobic capacity test $(\mathrm{ACT})$ in the off season and pre-season $(n=9)$. Values are mean (SD). $-24 h,-0.5 h,+6 h$, and $+24 h$ indicate 24 hours before, 0.5 hours before, 6 hours after, and 24 hours after the start of the ACT. No season main effect; no season by distance interaction; data collapsed across season: *values different from previous distance $p<0.001 ; \dagger$, t†values different from $5 \mathrm{~km}$ distance $(p<0.01$ and $p<0.001$ respectively).
Take home message

- TG and FFA concentrations at the beginning of exercise $(5 \mathrm{~km}$ and $10 \mathrm{~km}$ respectively) were much higher than expected.

- A logarithmic decrease in TG concentrations occurred during the first $20 \mathrm{~km}$ of prolonged running.

- Significantly different patterns of TG concentration during prolonged running were found in the OS and PS, indicating an effect of the training status with respect to the aerobic capacity of prolonged exercise on the amount of logarithmic decrease in TG concentration.

- Notably, in our well trained subjects during prolonged exercise near the AT, the pattern of glucose and insulin concentrations did not differ between the two seasons.

not find any differences in glucose, insulin, and lactate between the two training seasons during the ACT. The ACT was performed at an intensity similar to that of competition.

A limitation of this study was the acceptance of individual training schedules. Nevertheless, all athletes performed their training with the goal of improving aerobic capacity for prolonged exercise between the OS and PS. In accordance with the usual training studies, this should occur mainly through an increase in training volume. Our subjects increased their training volume by $46 \%$ from the OS to PS. The hypothetical improvement in aerobic capacity for prolonged exercise in the PS compared with the OS is documented by a significantly increased speed in the PS at AT, $4.0 \mathrm{mmol} / \mathrm{l} \mathrm{LT}$, and $2.0 \mathrm{mmol} / \mathrm{l}$ LT (table 4). The assessments of AT and LT are considered to be predictive of competition performance in well trained, long distance athletes. ${ }^{2}$ Nevertheless, there was a decrease in $\dot{\mathrm{V}}_{2} \mathrm{MAX}$ (table 4). However, this is in line with the knowledge that the assessment of $\dot{\mathrm{VO}}_{2} \mathrm{MAX}$ is not a valid indicator of aerobic capacity for prolonged exercise in elite triathletes ${ }^{2}$ and long distance runners. ${ }^{3}$ Although the absolute running speed in the ACT did not differ between seasons, intensity expressed as a percentage of speed at $2.0 \mathrm{mmol} / \mathrm{l}$ LT was significantly lower in the PS (table 4). Together, our findings strongly indicate that aerobic capacity for prolonged exercise was higher in the PS than the OS. Because we did not have a control group, we cannot exclude factors other than the training state, which may have influenced the time course of changes in circulating energy sources during prolonged exercise. However, the training state and the intensity may have the greatest influence on our results. Another limitation of this study is that certain conditions during the field test in the OS and PS were not identical. In particular, the ambient temperature was different. As performance variables may depend on climatic conditions, temperature related effects on our results may have been possible. ${ }^{36}$ Comparable investigations in laboratory conditions may not be tolerated by the athletes and may not be applicable. Although the ACT was conducted in the field, we attempted to standardise as many factors as possible to reduce the variability between the trials. The two test periods (four day sessions) were structured similarly (training regimen, nutritional intake, testing order, and timing). During the ACT, we asked the athletes to drink exactly $200 \mathrm{ml}$ water every $5 \mathrm{~km}$ followed by three minute rest intervals. With this schedule, changes in blood volume, determined from haemoglobin concentration and packed cell volume, were minimal during the ACT and similar in both seasons. However, to be really sure that shifts in plasma 
volume were not affecting TG or FFA measurements, calculation of plasma volume from total proteins or glycerol would have given additional information. Athletes performed in the ACT at a similar speed and near their individual AT (table 4).

At an exercise intensity comparable to competition, the availability and use of circulating substrate sources is controversial. Our study was performed with elite athletes at an aerobic high intensity exercise (near the AT) during a $25 \mathrm{~km}$ run comparing different training seasons with changes in circulating energy sources that occurred during prolonged exercise.

\section{Authors' affiliations}

B Knoepfli, Alpine Children's Hospital, Davos, Switzerland

M C Riddell, York University, York, UK

E Ganzoni, A Burki, Swiss Triathlon Association

B Villiger, TSH Chest Clinic and Swiss Olympic Center

S P von Duvillard, California State Polytechnic University, Pomona, CA, USA

\section{REFERENCES}

1 Franklin BA, Fletcher GF, Gordon NF, et al. Cardiovascular evaluation of the athlete (issues regarding performance, screening and sudden cardiac death). Sports Med 1997;24:97-119.

2 Rowbottom DG, Keast D, Garcia-Webb P, et al. Training adaptation and biological changes among well-trained male triathletes. Med Sci Sports Exerc 1997;29:1233-9.

3 Costill DL, Branam G, Eddy D, et al. Determination of marathon running success. Int Z Angew Physiol 1991;29:249-54.

4 Tanaka K, Watanabe $\mathrm{H}$, Konishi $\mathrm{Y}$, et al. Longitudinal associations between anaerobic threshold and distance running performance. Eur J Appl Physiol 1986;55:248-52.

5 Phillips SM, Green HJ, Tarnopolsky MA, et al. Effect of training duration on substrate turnover and oxidation during exercise. J Appl Physiol 1996;81:2182-91.

6 Brooks GA, Mercier J. Balance of carbohydrate and lipid utilization during exercise: the "crossover concept". J Appl Physiol 1994;76:2253-61.

7 Coggan AR, Kohort WM, Spina RJ, et al. Endurance training decreases plasma glucose turnover and oxidation during moderate-intensity exercise in men. J Appl Physiol 1990;68:990-6.

8 Romijn JA, Coyle EF, Sidossis LS, et al. Regulation of endogenous fat and carbohydrate metabolism in relation to exercise intensity and duration. Am J Phsiol 1993;265:E380-91.

9 Costill DL, Coyle E, Dalsky GP, et al. Effect of elevated plasma FFA and insulin on muscle glycogen usage during exercise. J Physiol 1977;43:695-9.

10 Hickson RC, Rennie MJ, Conlee RK, et al. Effects of increased plasma fatty acids on glycogen utilization and endurance. J Physiol 1977;43:829-33.

11 Holloszy JO, Coyle EF. Adaptation of skeletal muscle to endurance exercise and their metabolic consequences. J Appl Physiol 1984;56:831-8.

12 Hoppeler $\mathrm{H}$, Howald $\mathrm{H}$, Consley K, et al. Endurance training in humans: aerobic capacity and structure of skeletal muscle. J Appl Physiol 1985;59:320-7.
13 Saltin B, Astrand PO. Free fatty acids and exercise. Am J Clin Nutr 1993;57:752S-8S

14 Oberholzer F, Claassen $\mathrm{H}$, Moesch $\mathrm{H}$, et al. Ultrastrukturelle, biochemische und energetische Analyse einer extremen Dauerleistung (100 km-Lauf). Schweiz Z Sportmed 1976;24:71-98.

15 Felig P, Cherif A, Minagawa A, et al. Hypoglycemia during prolonged exercise in normal men. N Engl J Med 1982;306:895-900.

16 Wagenmakers AJM, Beckers EJ, Brouns F, et al. Carbohydrate supplementation, glycogen depletion, and amino acid metabolism during exercise. Am J Phsiol 1991;260:E883-90.

17 Millar-Stafford ML, Sparling PB, Rosskopf LB, et al. Carbohydrate-electrolyte replacement improves distance running performance in the heat. Med Sci Sports Exerc 1992;24:934-40.

18 Hargreaves $M$. Interactions between muscle glycogen and blood glucose during exercise. Exerc Sport Sci Rev 1997:25:21-39.

19 Ahlborg B, Bergström J, Ekelund LG, et al. Muscle glycogen and muscle electrolytes during prolonged physical exercise. Acta Physiol Scand 1967;70:129-42.

20 Vandenburghe K, Hespel P, Vanden Eynde B, et al. No effect of glycogen level on glycogen metabolism during high intensity exercise. Med Sci Sports Exerc 1995;27:1278-83.

21 Bangsbo J, Graham TE, Kiens B, et al. Elevated muscle glycogen and anaerobic energy production during exhaustive exercise in man. J Physiol 1992:451:205-27.

22 Wilber RL, Moffat RJ. Influence of carbohydrate ingestion on blood glucose and performance in runners. Int $J$ Sport Nutr 1992;2:317-27.

23 Tsintzas OK, Liu R, Williams C. The effect of carbohydrate ingestion during exercise on a $30 \mathrm{~km}$ race. Int J Sport Nutr 1993;3:127-39.

24 Knapik J, Wright J, Welch $M$, et al. Metabolic and cardiorespiratory parameters during three consecutive days of exhaustive running. J Sports Med Phys Fitness 1990;30:132-7.

25 Martin III WH, Dalsky GP, Hurley BF, et al. Effect of endurance training on free fatty acid turnover and oxidation during exercise. Am J Phsiol 1994;265:E708-14

26 Pitsiladis YP, Smith I, Maughan RJ. Increased fat availability enhances the capacity of trained individuals to perform prolonged exercise. Med Sci Sports Exerc 1999;31:1570-9.

27 Jeukendrup AE, Saris WHM, Van Diesen R, et al. Effect of endogenous carbohydrate availability on oral medium-chain triglyceride oxidation during prolonged exercise. J Appl Physiol 1996;80:949-54.

28 Jeukendrup AE, Saris WHM, Schrauwen P, et al. Metabolic availability of medium-chain triglycerides coingested with carbohydrates during prolonged exercise. J Appl Physiol 1995;79:756-62.

29 Massicotte D, Péronnet F, Brisson GR, et al. Oxidation of exogenous mediumchain free fatty acids during prolonged exercise: comparison with glucose. J Appl Physiol 1992;73:1334-9.

30 Lehmann M, Berg A, Kapp R, et al. Correlation between laboratory testing and distance running performance in marathoners of similar performance ability. Int J Sports Med 1983;4:226-30.

31 Wright RR, Tono M, Pollycove M. Blood volume. Semin Nucl Med 1975:5:63-78.

32 Jansson ED, Kaiijser L. Substrate utilization and enzymes in skeletal muscle of extremely enduranced-trained men. J Appl Physiol 1987;62:999-1005.

33 Hawley JA. Carbohydrate-loading and exercise performance (an update). Sports Med 1997;24:73-81.

34 Bergström J, Hermansen L, Hultman E, et al. Diet, muscle glycogen and physical performance. Acta Physiol Scand 1967;71:140-50.

35 Karlsson J, Saltin B. Diet, muscle glycogen, and endurance performance. J Appl Physiol 1971;31:203-6.

36 Galloway SDR, Maughan RJ. Effects of ambient temperature on the capacity to perform prolonged cycle exercise. Med Sci Sports Exerc 1997;29:1240-9. 